\title{
IZAZOVI SAKUPLJANJA OTPADA U RURALNIM I RAZUĐENIM NASELJIMA I PREPORUKE ZA USPOSTAVLJANJE ODGOVARAJUĆEG SISTEMA NA PRIMJERU OPŠTINE UGLJEVIK
}

\section{CHALLENGES OF WASTE COLLECTION IN RURAL AND DISPERSED SETTLEMENT AND RECOMMENDATIONS FOR THE ESTABLISHMENT OF AN APPROPRIATE SYSTEM ON THE EXAMPLE OF THE MUNICIPALITY OF UGLJEVIK}

\begin{abstract}
Biljana Gavrić, Bojan Batinić, Fakultet tehničkih nauka, Novi Sad
\section{Oblast - INŽENJERSTVO ZAŠTITE ŽIVOTNE} SREDINE

Kratak sadržaj - U ovom radu su opisani izazovi sakupljanja otpada u ruralnim i razudenim naseljima i preporuke za uspostavljanje odgovarajućeg sistema na primjeru opštine Ugljevik. Opisane su kategorije i faktori koji utiču na sistem sakupljanja otpada. Analiziran je trenutni sistem upravljanja otpadom, načini sakupljanja i transporta otpada u Rep. Srpskoj. Glavni dio predstavlja trenutno stanje sakupljanja otpada u opštini Ugljevik, $i$ definisanje odgovarajućeg sistema za sakupljanje otpada u naseljima koja trenutno nisu pokrivena uslugom sakupljanja. Konačno posmatrana su 4 scenarija sakupljanja otpada u navedenim naseljima i prikazani osnovni operativni i investicioni troškovi kao i teoretski prihod od prodaje izdvojeni sekundarnih sirovina.

Ključne reči: upravljanje čvrstim otpadom, sakupljanje otpada, ruralna i razuđena naselja

Abstract - In this paper is described challenges of waste collection in rural and dispersed settlement and recom-

Velike površine sakupljanja u posebnim područjima, odabir pravilnog metoda $\mathrm{i}$ distribucije otpada predstavljaju prepreke kojima se susreću komunalna preduzeća u aspektu pravilnog sakupljanja otpada u ruralnim područjima [1]. Zbog specifičnih karakteristika ruralnih i razuđenih mjesnih zajednica neophodno je prilagoditi i sistemu sakupljanja otpada. Proširivanje teritorije opštine servisom sakupljanja i odvozom otpada rješavaju se problemi pojave velikog broja divljih deponija čime se riješava veliki ekološki problem [2]. Neadekvatno sakupljanje, transport i odlaganje otpada predstavlja jedan od najvećih ekoloških problema $u$ Republici Srpskoj. Glavni problemi nalaze se u nedostaku pravnog i institucionalnog okvira, nedosljednoj primjeni i propustima prilikom primjene zakona i drugih akata, nedostatku infrastrukture, visokim troškovima, neracionalnoj organizaciji, niskom kvalitetu usluga, ali i nedovoljnoj brizi za zaštitu životne sredine, kao i nedovoljnoj uključenosti javnosti u rješavanje ovog problema [3].
\end{abstract} mendations for the establishment of an appropriate system on the example of the municipality of Ugljevik. This paper describes the categories and factors that influence the waste collection system. The current management, way of collecting and transporting waste in Republika Srpska is also covered. The main part of the paper is current state of collection of waste in the municipality of Ugljevik, and the definition of an appropriate waste collection system in settlements that are not currently covered by the collection service. Finally, 4 scenarios of waste collection in the abovementioned settlements were analyzed and the basic operational and investments costs as well as the theoretical income from the sale of extracted secondary raw materials were shown.

Keywords: solid waste management, waste collection, rural and dispersed settlement

\section{UVOD}

Ruralno područje se znatno razlikuje od urbanog područja po mnogo čemu, u pogledu ekonomije, usluga, socijalne strukture i stavova. Tako i upravljanje otpada varira u ruralnim i urbanim područjima jedno od drugog.

\section{NAPOMENA:}

Ovaj rad proistekao je iz master rada čiji mentor je bio doc. dr Bojan Batinić.

\section{UPRAVLJANJE OTPADOM}

Upravljanje čvrstim otpadom je globalni izazov, posebno u zemljama u razvoju[4]. Sa narušavanjem životne sredine, odnosno čovjekovom proizvodnjom i potrošnjom proizvoda sve je veća i potreba za upravljanjem otpadom, što kao rezultat daje bezbjednu i pouzdanu tehnologiju kao što su: moderni sakupljački sistemi, recikliranje, insineratori i moderne deponije. Utvrđivanje količine i morfološkog sastava otpada predstavlja polaznu osnovu za uspješno upravljanje komunalnim otpadom, odnosno stvaranje preduslova za:

- dobijanje tačnih podataka o količini i sastavu otpada na lokalnom i nacionalnom nivou,

- strateško planiranje u oblasti upravljanja otpadom,

- sagledavanje mogućnosti za sprovođenje i projektovanje određenih tretmana otpada (reciklaža, kompostiranje, deponovanje, termički tretman i slično),

- ocjenu uspješnog primjenjenog modela ili tretmana upravljanja otpadom,

- definisanje neophodne opreme za sakupljanje i tranport otpada,

- identifikaciju opasnih komponenti u otpadu, 
- ocjene nivoa primjene Direktiva i zakonskih odredbi,

- $\quad$ praćenje sezonskih promjena u količini i sastavu otpada,

- projekcija budućih količina i sastava otpada [5].

\section{NAČINI SAKUPLJANJA OTPADA I OPIS NEOPHODNE OPREME}

Prema Okvirnoj direktivi o otpadu ,sakupljanje“ je definisano kao: „sakupljanje otpada, uključujući preliminarno sortiranje i skladištenje otpada za potrebe transporta do postrojenja za tretman otpada. Sakupljanje je početak svih procesa upravljanja otpadom [6]. Prema Bilitevskom i dr (1997), svaki sistem sakupljanja otpada je definisan kao kombinacija tehnologije i ljudskog rada kao što su:

- Metode sakupljanja,

- Sistem kontejnera,

- Vozila,

- Radnika [7].

Sakupljanje otpada je sakupljanje čvrstog otpada iz mjesta proizvodnje (stambene, komercijalne industrije, institucionalne jedinice) do tačke tretmana ili odlaganja. Sakupljanje čvrstog otpada iz opština se može podijeliti na 3 metode:

1) sa centralizovane lokacije za sakupljanje otpada,

2) izvan ili uz zgradu, duž ulice ili staze,

3) sakupljanje od vrata do vrata [7].

Posude igraju veoma važnu ulogu u upravljanju otpadom i sistemu za sakupljanje otpada. One osiguravaju da nastali otpad bude efikasno i mehanizovano sakupljen [9]. Vrste vozila za sakupljanje mogu se podjeliti u sledeće 3 grupe:

- Vozila sa jednostavnim načinom pražnjenja,

- Vozila za kontejnere,

- Specijlna vozila.

Kamioni sa zadnjim utovarom spadaju u grupu vozila sa jednostavnim načinom pražnjenja. Ovaj tip kamiona podiže kontejnere sa pneumatskim ili hidrauličnim uređajem. Pneumatski uređaj podiže i naginjanje kontejner sa zadnje strane, zatim ga spušta na vozilo i prazni. Vozilo sa zadnjim utovarom je u upotrebi već duži niz godina i još uvijek je najčešće vozilo za prikupljanje komunalnog otpada u gradskom području. Zbog uskih ulica i ograničenog prostora za proces sakuljanja bočna i prednja utovarna vozila ne mogu efikasno raditi $u$ urbanim područjima. Da bi se efikasno upravljalo sistemima sakupljanja otpada važnu ulogu igra i osoblje za utovar, koji prazne kontejnere/kanti. Broj osoblja po vozilu zavisi od velikog broja faktora kao što su veličina i različiti tipovi kontejnera/kanti koji se koriste, udaljenost kontejnera i sastav otpada sakupljanja [10].

\section{FAKTORI KOJI UTIČU NA SISTEM SAKUPLJANJA OTPADA}

Ukupni troškovi sakupljanja uključuju operativne troškove i početne troškove. Operativni troškovi su logistički, podsticajni i ekološki troškovi, dok početni troškovi sadrže investicije u objekte za sakupljanje i opremu [11]. Prema različitim istraživanjima, glavni troškovi i opterećenje sistema komunalnog sakupljanja otpada javlja se direktno iz transporta, od kilometara i vremena koji su napravili kamioni za sakupljanje otpada. Administracija upravljanja otpadom u ruralnim opštinama ,pati“ od nedostatka pitanja nadležnosti i finansijskih sredstava. Još jedan važan faktor u upravljanju otpada je administrativni značaj, koji u ruralnim područjima pati od mnoštvo različitih zadataka javnih službenika i nedostatka saradnje i finansijskih sredstava [12]. Iskustva širom svijeta pokazuju da je odvojeno sakupljanje čvrstog otpada na izvoru efikasan metod za smanjenje i poboljšanje reciklaže otpada. Prikupljeni otpad na izvoru može ne samo da uštedi troškove transporta, već se može doprinjeti recikliranju otpada i samim tim preusmjeriti čvrsti otpad dalje od deponije [13].

\section{UPRAVLJANJE OTPADOM U REPUBLICI SRPSKOJ}

Konstantan rast količine proizvedenog otpada, smanjivanje mogućnosti i lokacije za deponovanje otpada i promjena zakonodavnih i insititucionalnih okvira imaju veliki uticaj na planiranje sistema upravljanja otpada u Republici Srpskoj. Upravljanje komunalnim otpadom iz domaćinstava u Republici Srpskoj se sastoji od najmanje tri osnovne faze:

1) skupljanje na mjestu nastajanja otpada (obično blizu stambenog objekta ili na zajedničkoj lokaciji za više kontejnera);

2) transport od područja sakupljanja otpada do mjesta za tretman / odlaganje vozilima za sakupljanje;

3) odlaganje na odlagalištima/deponijama.

Komunalni otpad sa teritorije Republike sakupljaju uglavnom javna komunalna preduzeća (u prosjeku jedno preduzeće po jedinici lokalne samouprave) sa prosječnim voznim parkom koji se sastoji od specijalizovanih kamiona (tkz. „smećari“) sa prosječnom korisnom nadogradnjom od oko $14 \mathrm{~m}^{3}$, auto-dizačem kontejnera veće zapremine $\left(5 \mathrm{~m}^{3} \mathrm{i} 7 \mathrm{~m}^{3}\right)$, te ostalih vozila (kamioni, traktori sa prikolicom, čistilice ulica itd). U većini urbanih dijelova opština komunalni otpad se prikuplja svakodnevno ili svaki drugi dan, dok se frekvencija smanjuje na jednom sedmično u predgrađima, do jednom ili dva puta mjesečno u ruralnim područjima. Organizovano prikupljanje razdvojenog komunalnog otpada iz domaćinstava u Republici Srpskoj ne postoji i nije u upotrebi. Urbani dijelovi opština i prigradska naselja su veoma dobro obuhvaćeni sistemom prikupljanja otpada uprkos nedostatku modernih vozila za sakupljanje otpada i nedovoljnom kapacitetu kontejnera, kao i problemima sa finansiranjem. Međutim, problemi su izrazito izraženi u nepokrivenosti usluga u ruralnim dijelovima opština, što je posljedica neodgovarajuće infrastrukturne opremljenosti, dostupnosti, organizacije i nedovoljnih finansijskih sredstava, te se može konstatovati da je pokrivenost uslugama prikupljanja otpada nedovoljna [3].

\section{ANALIZA SAKUPLJANJA OTPADOM U OPŠTINI UGLJEVIK}

Opština Ugljevik se nalazi u sjeveroistočnom dijelu Republike Srpske, na istočnim padinama planine Majevice prema Semberiji. Grad Ugljevik koji je ujedno i 
centar opštine smješten je na dvadeset prvom kilometru regionalnog puta M-18 Bijeljina-Tuzla. Urbani dio opštine je kompletno pokriven servisom sakupljanja i odvoza komunalnog čvrstog otpada (Mjesna Zajednica Centar, Sjever i Novo Naselje) i sedamnaest ruralnih mjesnih zajednica djelimično su pokrivene servisom sakupljanja i odvoza komunalnog čvrstog otpada i dvije zajednice koje nisu pokrivene sistemom sakupljanja otpada (tabela 1). Što se tiče naseljenosti manji dio površine opštine Ugljevik zauzima urbani dio (mjesne zajednice Centar, Sjever i Novo Naselje) na kome živi oko $40 \%$ stanovništva opštine a veći dio stanovništva oko $60 \%$ živi u ruralnom području [14].

\begin{tabular}{|c|c|c|c|c|c|}
\hline Naziv M.Z. & $\begin{array}{c}\text { Broj } \\
\text { stanovnika }\end{array}$ & $\begin{array}{c}\text { Broj } \\
\text { domaćinstava }\end{array}$ & $\begin{array}{c}\text { Broj korisnika usluga } \\
\text { sakupljanja otpada }\end{array}$ & Da li postoji odvoz & Mogući odvoz zimi \\
\hline Ugljevik & 3922 & 1249 & 1309 & $\mathrm{Da}$ & $\mathrm{Da}$ \\
\hline Bogutovo Selo & 294 & 120 & 87 & $\mathrm{Da}$ & $\mathrm{Da}$ \\
\hline Mukat-Stankovići & 330 & 113 & - & $\mathrm{Da}$ & $\mathrm{Da}$ \\
\hline Donja Krćina & 136 & 49 & - & $\mathrm{Ne}$ & $\mathrm{Ne}$ \\
\hline Gornja Krćina & 167 & 62 & 297 & $\mathrm{Da}$ & $\mathrm{Da}$ \\
\hline Donja Trnova & 1154 & 368 & 383 & $\mathrm{Da}$ & $\mathrm{Da}$ \\
\hline Zabrđe & 1551 & 467 & 66 & $\mathrm{Da}$ & $\mathrm{Da}$ \\
\hline Glinje & 461 & 134 & 220 & $\mathrm{Da}$ & $\mathrm{Da}$ \\
\hline Ugljevička Obrijež & 945 & 294 & 147 & $\mathrm{Da}$ & $\mathrm{Da}$ \\
\hline Ugljevik Selo & 478 & 166 & 70 & $\mathrm{Da}$ & $\mathrm{Da}$ \\
\hline Gornja Trnova & 284 & 99 & 54 & $\mathrm{Da}$ & $\mathrm{Da}$ \\
\hline Janjari & 497 & 166 & 56 & $\mathrm{Da}$ & $\mathrm{Da}$ \\
\hline Atmačí́i & 429 & 132 & 109 & $\mathrm{Da}$ & $\mathrm{Da}$ \\
\hline Korenita & 557 & 186 & 92 & $\mathrm{Da}$ & $\mathrm{Da}$ \\
\hline Maleševci & 404 & 127 & 90 & $\mathrm{Da}$ & $\mathrm{Da}$ \\
\hline Stari Ugljevik & 707 & 254 & 126 & $\mathrm{Da}$ & $\mathrm{Da}$ \\
\hline Mezgraja & 459 & 168 & 147 & $\mathrm{Da}$ & $\mathrm{Da}$ \\
\hline Ravno Polje & 598 & 192 & 221 & $\mathrm{Da}$ & $\mathrm{Da}$ \\
\hline Tutnjevac & 1042 & 322 & 23 & $\mathrm{Da}$ \\
\hline Srednja Trnova & 579 & 159 & $\mathbf{3 5 5 5}$ & & \\
\hline Ukupno & $\mathbf{1 4 9 9 4}$ & $\mathbf{4 8 2 7}$ & & & \\
\hline
\end{tabular}

Tabela 1. Broj domaćinstava i korisnika usluga sakupljanja otpada po mjesni zajednicama

Servisom sakupljanja i odvoza komunalnog otpada trenutno je pokriven gradski dio opštine (mjesna zajednica Centar) odnosno zgrade kolektivnog stanovanja u kojima je smješteno oko 1249 korisnika usluga odvoza smeća i isti odlažu svoj otpad na centralizovanim lokacijama u postavljenim kontejnerima zapremine $1,1 \mathrm{~m}^{3}$ i $5 \mathrm{~m}^{3}$. Trenutno je postavljeno 46 kontejnera navedene zapremine rasporećenih na 39 lokacija. Prigradski dio (mjesne zajednice Novo naselje, Sjever) odnosno individualni stambeni objekti su takođe kompletno pokriveni uslugom sakupljanja i odvoza otpada, korisnici usluga odvoza smeća svoj otpad odlažu u vlastite kante i kontejnere postavljene na određenim lokacijama. Seoske mjesne zajednice koje su pokrivene servisom sakupljanja i odvoza otpada, svoj otpad odlažu u vlastite kante zapremine 1201 koje su postavljene duž ulice, u blizini škola, groblja su postavljeni kontejneri zapremine $1,1 \mathrm{~m}^{3}$. Studijom su analizirane dvije mjesne zajednice opštine Ugljevik, Donja i Gornja Krćina, jer predstavljaju područja gdje nije pokriven sistem sakupljanja otpada. Pored toga ove dvije mjesne zajednice su uzete u razmatranje jer su ruralno i razuđenog karaktera.

Analiziranje naselja proizašlo je iz potrebe studije da dobije podatke na uporediv način i da dobijeni podaci posluže kao osnova za definisanje budućeg sistema sakupljanja u datim naseljima, ali i polazna osnova za utvrđivanje sistema za naselja sličnih karakteristika. Da bi se procjenio najefikasniji i ekonomski najisplativiji način sakupljanja otpada, uvedena su 4 scenarija, scenariji A 1 i A 2 sa kontejnerima od $1,1 \mathrm{~m}^{3}$ ( scenario A 1 - na definisanoj lokaciji sakupljanje mješovitog otpada i scenario A 2 - odvojeno sakupljanje (mokri i suvi otpad)) i scenariji B 1 i B 2 sa kantama od 1201 (scenario B 1 sakupljanje mješovitog otpada za svako domaćinstvo i scenario B 2 - odvojeno sakupljanje otpada (mokri i suvi otpad)). Ova četiri scenarija međusobno su upoređivana u pogledu ekonomskih faktora (investicionih i operativnih troškova) i teoretski prihoda izdvajanja sirovine i prodaje na tržištu (mogućnost reciklaže) (grafički prikazi 1. i 2.). Investicioni troškovi Donje i Gornje Krćine su najmanji u scenariju B 1 i B 2, tj postavljanjem jedne kante od 1201 za svako domaćinstvo, zbog malog broja domaćinstava. $\mathrm{Za}$ datu studiju povećanjem broja domaćinstava sistem sa pojedinačnim kantama postala bi u jednom momentu skuplja opcija. Troškovi su izračunati u zavisnosti od broja stanovništva, prosječne udaljenosti domaćinstava od kontejnera/kante i cijene kontejnera/kanti.

Najveću ulogu igra cijena kontejnera/kanti na tržištu. U konkretnom slučaju, poređenjem svih analiza scenarija, može se zaključiti da razlika među njima može biti i do 6.000 EUR na godišnjem nivou, uz napomenu da navedeni troškovi u velikoj mjeri zavise od broja domaćinstava, tj. veličine posmatranog naselja. Po sličnom principu operativni troškovi se mjenjaju sa udaljenošću i brojem lokacija postavljenih kontejnera/kanti, tako je i utrošak goriva za scenarija A 1 i A 2 manji za \pm 600 EUR u odnosu na B 1 i B 2.

Teoretski prihodi od prodaje sirovine najpovoljniji je za scenario B 2 gdje najvažniju ulogu ima procenat efikasnosti izdvajanja na liniji, zbog pretpostavke da će u tom scenariju efikasnost primarne separacije otpada, tj. izdvajanja reciklabilnih materijala od strane građana biti najveće. Praksa je pokazala da kvalitetno razdvajanje 
otpada na izvoru, u ovom slučaju u dvije kante, daje najveće rezultate na kraju tj. na liniji za separaciju.

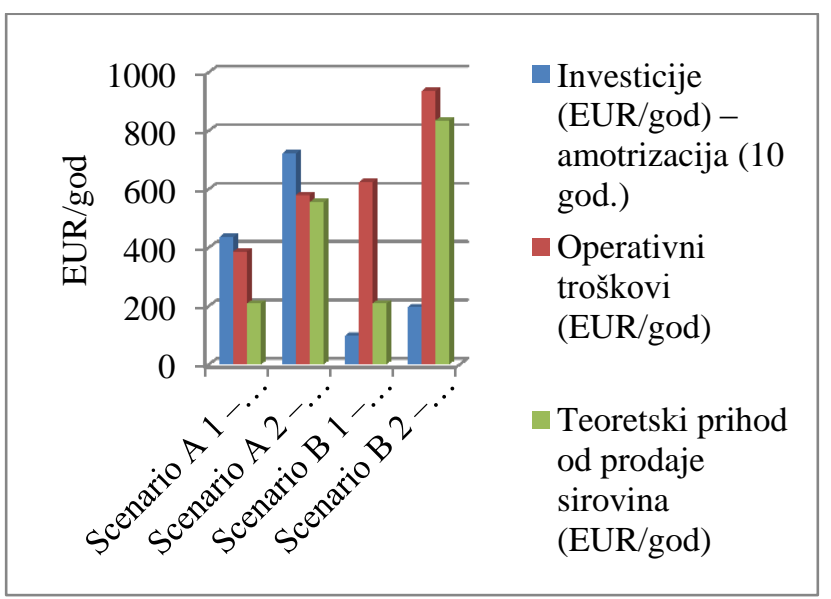

Grafik 1. Odnos troškova i teoretskog prihoda za Donju Krćinu

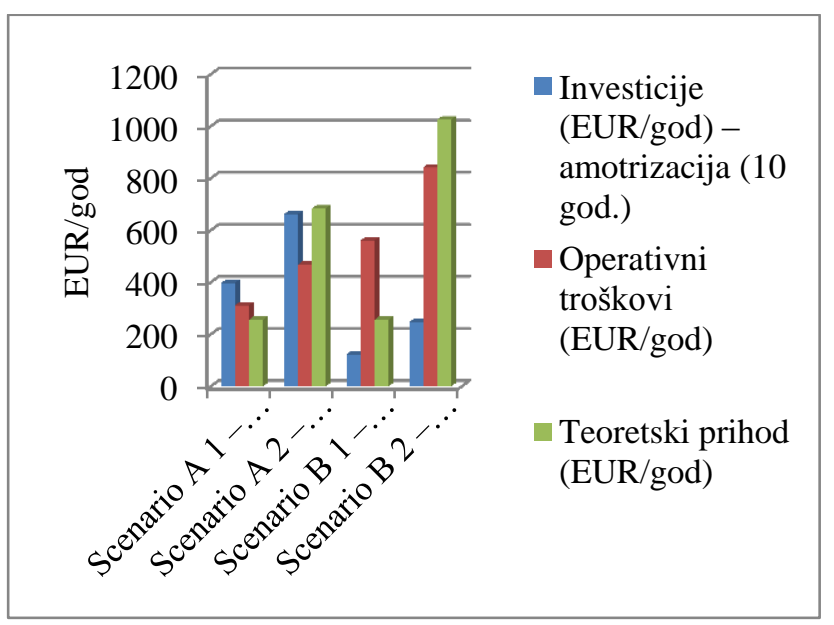

Grafik 2. Odnos troškova i teoretskog prihoda za Gornju Krćinu

\section{ZAKLJUČAK}

Velike površine sakupljanja u posebnim područjima, odabir pravilnog metoda $\mathrm{i}$ distribucije otpada predstavljaju prepreke kojima se susreću komunalna preduzeća u aspektu pravilnog sakupljanja otpada u ruralnim i razuđenim područjima. Sakupljanje je početak svih procesa upravljanja otpadom. Sakupljanje u ruralnim i razuđenim naseljima predstavlja izazov za JKP, kroz rad i analizu četiri različita scenarija u opštini Ugljevik pokazano je da odabir različitih metoda i opreme za sakupljanje može značajno da utiče na investicione i operativne troškove, kao i potencijalni prihod od prodaje reciklabilnih sirovina.

Navedeni primjeri mogu da posluže kao osnova za definisanje odgovarajućeg/budućeg sistema sakupljanja u datim naseljima, ali i polazna tačka za utvrđivanje sistema za naselja sličnih karakteristika koja nisu bila predmet analize.

\section{LITERATURA}

[1] Florin C.M. 2017. Solid Waste Management in Rural Areas. InTech, London, United Kingdom
[2] Lokalni plan upravljanja otpadom opštine Ugljevik 2011-2016.godine. jun 2011, Opština Ugljevik, Bosna i Hercegovina

[3] Topić M i dr. 2011. Upravljanje otpadom u Republici Srpskoj - Analiza postojećeg stanja sa posebnim osvrtom na komunalna preduzeća, CIP - Katalogizacija u publikaciji Narodna i univerzitetska biblioteka Republike Srpske, Banja Luka, Bosna i Hercegovina

[4] Zhizong H. Young L. Min Z. Guozhong S. Qibin L. Dan Z. Yu Z. Yongqiang F. Yanhua X. 2017. Influencing factors of domestic waste characteristics in rural areas of developing countiries. Waste Management 2017(72):45-54 [5] Vujić G, Ubavin D, Stanisavljević N, Batinić B. 2012. Upravljanje otpadom u zemljama u razvoju. Fakultet tehničkih nauka, Novi Sad

[6] European Commission (EU), Guidance on the interpretaiton of key provisions of Directive 2008/98/EC on waste, European Commission. june 2012

[7] Bilitewski B. Hardtle G. Marek K. 1997. Waste Managment. Springer, Berlin, Germany

[8] Cvetanović B. 2017. Planiranje procesa sakupljanje otpada. Visoka tehnička škola strukovnih studija Niš

[9] Vujić G. Brunner P. H. 2009. Održivo upravljanje otpadom. Fakultet tehničkih nauka, Novi Sad

[10] Kogler T. 2007. Waste collection. A report with support from the ISWA Working Group on Collection and Transportation Technology

[11] Jahre Marianne, 1994. Collection schemes for household waste: description and classification. Report of Ph.D. thesis „Logistics Systems for Recycling - Efficient Collection of Household Waste. Handelshoyskolen Bl, Norwegian School of Management, Bl Research Center

[12] Poldnurk J. 2015. Optimisation of the economic, environmental and administrative efficiency of the municipal waste managment model in rural areas. Resources, Conservation and Recycling 2015 (97): 55-65 [13] Zeng C. Niu D. Hangfen L, Zhou T. Zhao Y. 2016. Public perceptions and economic values of sourceseparated collection of rural solid waste: A pilot study in China. Resources, Conservation and Recycling 2016 (107): 166-173

[14] Lokalni plan upravljanja otpadom opštine Ugljevik 2011-2016.godine. jun 2011. Opština Ugljevik, Bosna i Hercegovina

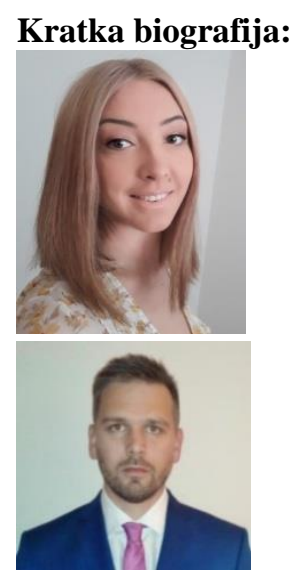

Biljana Gavrić rođena je 3. maja 1991. godine u Tuzli. Osnovnu i srednju školu završila je u Ugljeviku. Diplomski - master rad odbranila je 2019.godine na Fakultetu tehničkih nauka iz oblasti Inženjerstvo zaštite životne sredine.

Bojan Batinić rođen je 1981. godine u Zagrebu. Master studije na studijskom programu inženjerstvo zaštite životne sredine na Fakultetu tehničkih nauka iz Novog Sada je završio 2008. godine. Doktorirao je 2015. godine na Fakultetu tehničkih nauka i iste godine izabran je u zvanje Docenta. 